\title{
Споры в Арктике: угрозы и возможности
}

\author{
Николоз Джанджгава*
}

\section{Введение}

В течение столетий Арктика была для человечества «святым местом». Эта замерзшая пустота была магнитом для авантюристов и исследователей, для всех, кто хотел бросить вызов себе или природе. В девятнадцатом веке «вершина мира» стала полем соперничества основных европейских и североамериканских стран. В этой гонке главным призом был Северный полюс. Какое государство первым заявит свои права на него? Даже в эпоху климакса колониальных завоеваний ни одна страна не была готова потребовать Арктику для себя полностью. Двадцатый век принес новое развитие событий в Арктике. Две мировые войны прошли почти незамеченными для Дальнего Севера. Но в период Холодной войны Арктика стала театром военных действий потому, что для двух сверхдержав - Соединенных Штатов и Советского Союза - маршрут через Арктику обеспечивал кратчайший путь для оснащенных ядерными боеприпасами межконтинентальных ракет и для самолетов, несущих термоядерные бомбы и направленные на цели в одной или в другой стране. Толстая ледяная шапка предоставляла дополнительную защиту атомным подлодкам, которые пытались прокрасться ближе к вражеской территории. После конца Холодной войны и падения коммунизма в Восточной Европе внимание к Арктике ослабло. В начале двадцать первого века Арктика встала перед новыми вызовами. Климатические изменения, глобальная гонка за природными ресурсами, новые транспортные маршруты и старые территориальные споры не только породили новые угрозы безопасности, но и новые возможности для сотрудничества между арктическими странами.

Целю этой статьи является рассмотрение проблем, которые появились в Арктике в эпоху после конца Холодной войны. Здесь будет проанализирована роль основных игроков в Арктике; территориальные споры между арктическими странами; суверенные права на природные ресурсы и споры о новых транспортных маршрутах. Особенно важно рассмотреть наращивание военного потенциала России и ее более напористую внешнюю политику в арктическом регионе.

Есть две основные причины, по которым Арктика во все большей степени становится центром глобальной политики. Первая причина - это изменение климата. Процесс глобального потепления является побочным продуктом человеческой деятельности, но до этого момента мировое сообщество не успело установить об-

\footnotetext{
Полковник Николоз Джанджгава является международным сотрудником Национального колледжа обороны в Национальном университете обороны в Вашингтоне, округ Колумбия. Его основная должность - офицер вооруженных сил Грузии. Взгляды, выраженные в этой статье, принадлежат автору и не отражают официальную политику или позицию Национального университета обороны, Министерства обороны или американского правительства.
} 
щие правила, направленные на сокращение использования ископаемого топлива и уменьшение эмиссий углекислого газа с тем, чтобы ограничить последствия климатических изменений. Таяние круглогодичного морского льда в Арктике открыло совершенно новые морские пути, а сокращение размеров полярных льдов в Арктике привело к обнаружению природных ресурсов, которые были скрыты на протяжении тысячелетий. Вторая причина - это восход России. Даже до войны с Грузией в 2008 году, Россия демонстрировала растущую склонность во все большей степени полагаться на «жесткую силу», а не на примат международного права. Наращивая националистическую риторику и все чаще предпринимая односторонние действия, российское политическое и военное руководство пытается пересмотреть и создать доктрину «Новой России».

\section{Основные игроки}

Есть пять арктических государств: Соединенные Штаты, Канада, Дания (из-за того, что ей принадлежит Гренландия), Норвегия и Россия. Кроме того, есть еще три страны с территорией, прилегающей или находящейся за Полярным кругом: Исландия, Швеция и Финляндия. В более широком смысле, Европейский Союз (ЕС) так же является одной из основных заинтересованных сторон во всех спорах в Арктике (с учетом статуса Дании, Швеции, Финляндии как членов ЕС). Эти восемь стран являются членами Арктического совета. Этот форум высокого уровня был создан в 1996 году для расширения сотрудничества между странами Арктики. Есть шесть рабочих групп, которые управляют рядом проектов - от положения о судоходстве на «Крайнем Севере» до оценки последствий изменения климата. Арктический совет работает по принципу консенсуса и не имеет ни регуляторных функций, ни механизма принуждения. ${ }^{1}$ Германия, Польша, Нидерланды, Франция, Испания и Великобритания имеют статус постоянных наблюдателей. Китай, Япония, Южная Корея и Италия имеют статус специальных ad hoc наблюдателей. Эти страны находятся далеко от Арктики, но они заинтересованы в участии в работе Арктического совета, чтобы формулировать права на морские перевозки (которые могут оказать влияние на их транспортные сети) и чтобы принимать участие в эксплуатации природных ресурсов Арктики.

\section{Территориальные споры}

Спорные границы являются основной проблемой безопасности для стран, граничащих друг с другом в Арктике. Эти проблемы включают не только споры о границах, но и вопросы права на проход, территориальные и международные воды, размер континентального шельфа и границы исключительной экономической зоны (ИЭЗ).

1 Alf Håkon Hoel, "The High North Legal-Political Regime," in Security Prospects in the High North: Geostrategic Thaw or Freeze?, ed. Sven Holtsmark and Brooke Smith-Windsor (Rome: NATO Defense College, May 2009), 95. 
Есть два международных закона, которые устанавливают принципы урегулирования противоречий между странами: Конвенция о континентальном шельфе от 1958 года и Конвенция ООН по морскому праву (КООНМП) от 1982 года. КООНМП гласит, что прибрежные государства обладают суверенными правами на природные ресурсы в пределах 200 морских миль от их берегов. Эти расширенные границы являются их Исключительной экономической зоной. За пределами ИЭЗ лежат международные воды, где действует право на свободные морские перевозки и право плавать под национальным флагом. Наиболее сложным является вопрос, где начинается и где кончается континентальный шельф. В соответствие с КООНМП, вне двухсотмильной зоны, юрисдикция прибрежного государства на континентальный шельф простирается дотуда, откуда начинается глубоководное морское дно. Минеральные ресурсы под глубоководным морским дном принадлежат всему человечеству. Чтобы заявить свои права на континентальный шельф, государства должны предоставить соответствующую информацию в Комиссии ООН по континентальному шельфу. ${ }^{2}$

Проблемы, связанные с установлением национальных границ и соответственно с Исключительной экономической зоной есть у всех арктических государств. К примеру, существует спор между Россией и США в Беринговом море; между США и Канадой о море Бофорта; между Канадой и Данией в связи с проливами Дэвиса; между Данией и Исландией по проливу Фрама; между Данией, Норвегией и Исландией о статусе острова Ян-Майена; и между Данией и Норвегией касательно острова Свалбард. Спор между Норвегией и Россией о морских границах в Баренцовом море был улажен в сентябре 2010 года. Сорокалетний спор о территории площадью в 175 квадратных километров государства разрешили поделив ее поровну. Существует и другой территориальный спор между Канадой и Данией о необитаемом острове Ханса, над которым и оба государства подняли когда-то свой национальный флаг. В 2005 году датский премьер-министр заявил «Давайте вместе будем использовать остров Ханса как символ мира и доброй воли, чтобы показать, как цивилизованные страны относятся с уважением друг к другу». ${ }^{3}$ Но проблема о суверенном праве на остров Ханс остается нерешенной.

\section{Новые маршруты морских перевозок}

Вопросы, касающиеся границ территориальных вод, связаны с правом на свободу морских перевозок и правом на проход через проливы. С таянием круглогодичного льда, в Арктике скоро могут быть открыты для навигации два новых маршрута. Климатологи предсказывают, что уже в 2015 году Северный ледовитый океан может на время освобождаться ото льда. Открытие двух проходов - СевероЗападного и Северо-Восточного - существенно сократит длину линии навигации между континентами. Северо-Западный проход тянется от пролива Ланкастер до

\footnotetext{
Там же, 87.

3 Michael Byers, Who Owns the Arctic? Understanding Sovereignty Disputes in the North (Vancouver, BC: Douglas \& McIntyre, 2010), 30.
} 
Берингова пролива. Северо-Восточный проход (или Северный морской путь, как называют его русские) следует сибирскому берегу. Основная разница между двумя проходами состоит в том, что Северо-Западный проход полностью лежит в канадских территориальных водах, тогда как Северо-Восточный лежит в основном в ИЭЗ России. ${ }^{4}$

Для Соединенных Штатов, свобода морского транспорта и морских линий коммуникаций является первостепенным приоритетом национальной безопасности. Соединенные Штаты не подписали КООНМП и считают, что оба прохода являются международными водами, которые не подчиняются национальному законодательству. Эта позиция приводит к возникновению напряженности не только в отношениях с Россией, но и в отношениях с соседом и многолетним союзником США - Канадой. В ноябре 2009 года Россия объявила, что она будет взимать с кораблей «справедливую» цену за пользование Северо-Восточным проходом; суда будут должны заранее подавать уведомление и заявление на навигационное руководство - все в соответствии с российскими законами. Что касается Северо-Западного прохода, Канада заявляет, что он является «внутренним морем», которое полностью попадает под канадский суверенитет. ${ }^{5}$

Последствия изменения климата будут играть жизненоважную роль в этой части света. Таяние льда открывает проходы между континентами, которые раньше полностью игнорировались. Расстояния между Европой и Азией по Северо-Западному (СЗП) или Северо-Восточному проходу (СВП) намного короче, чем маршруты через Суэцкий и Панамский канал. Расстояние от Роттердама до Йокохамы 13950 км по СЗП и 13360 по СВП, тогда как через Панамский канал 23470 км и 21170 через Суэцкий. ${ }^{6}$

Кроме расстояния, есть и другие факторы, которые оказывают влияние на навигационные решения. Основным недостатком обеих проходов является исключительно трудная навигация из-за льда и отрицательных температур во время долгой арктической зимы. Дрейфующие льды и айсберги являются серьезной опасностью для навигации. Глубина некоторых проливов невелика (не больше 13 метров, что является проблемой для больших грузовых судов) и портовая инфраструктура, где могли бы останавливаться океанские корабли неразвита. Для фирм, осуществляющие морские перевозки, время является наиболее ценным товаром; любые опоздания, из-за природных или антропогенных опасностей, могут оказать влияние на цену фрахта. Цена страховок будет выше. Новые суда с усиленным корпусом, с мощными средствами ночного видения и радиолокационного обзора, которые необходимы для навигации в таких опасных водах, еще больше поднимут цену перевозок. И это только часть ограничений, которые могут оказать влияние на перевозки по Северо-Западному и Северо-Восточному проходу.

4 Frédéric Lasserre, "High North Shipping: Myths and Realities," in Security Prospects in the High North, 179.

5 Stephen Blank, Russia in the Arctic (Carlisle, PA: Strategic Studies Institute Papers, U.S. Army War College, 2011), 27.

6 Lasserre, "High North Shipping: Myths and Realities," 193. 


\section{Права на природные ресурсы в Арктике}

Арктика является критически важной из-за наличия природных ресурсов. По оценкам Географического общества США (ГОСША) от 2008 года, приблизительно 22 процента из нераскрытых нефтяных и газовых ресурсов находятся на дне Арктического океана. В регионе предположительно лежат 83 миллиардов баррелей нефти, что достаточно для удовлетворения мирового спроса в течение трех лет. Газовые месторождения в объеме 44 триллионов кубических метров эквивалентны четырнадцати годам мирового потребления. Российский монополист Газпром потратит 20 миллиардов долларов США на разработку газового поля Стокман, которое по оценкам содержит 3,8 триллионов кубических метров природного газа. Норвежские фирмы эксплуатируют значительное (но меньшее) поле Шовит. Канадские и британские фирмы инвестируют 1,2 миллиарда долларов США в месторождения на канадской стороне моря Бофорта.

Проблемы энергетической безопасности проистекают из двух основных факторов: неравномерное распределение природных ресурсов между арктическими государствами и неурегулированные границы между ними. По оценкам организации «Геологический обзор США», основная часть нефтяных и газовых запасов лежит в неоспариваемых исключительных экономических зонах арктических государств. Крупнейшие доказанные запасы, газовые и нефтяные поля Восточной Сибири, находятся полностью в российской ИЭЗ. Между Россией и Норвегией было подписано соглашение для урегулирования границ в Баренцевом море в виду наличия в нем запасов нефти и газа. Но существуют большие проблемы с освоением этих ресурсов. С точки зрения интересов отрасли, крупные нефтяные компании оценивают возможности региона в смысле ресурсного потенциала, технологических проблем, издержек и рисков. Текущие деятельности нефтяных/ газовых компаний в арктическом регионе в основном ограничиваются бурением на берегу. С одной стороны, на берегу нефтяные запасы находятся на глубине не более 500 метров, что делает бурение в море весьма эффективным в ценовом отношении. С другой стороны, большая часть неразведанных ресурсов находятся под ледяной шапкой, где суровые погодные условия, в сочетании с циклом бурения, извлечения и транспортировки в среде с практически отсутствующей инфраструктурой, делает эти усилия очень дорогостоящими. Освоение нефтяных и газовых месторождений определяется рынком. Цена барреля нефти, добытой в Арктике, варьирует от 40 до 100 долларов США, тогда как цена нефти, добытой на Ближнем Востоке или в Северной Африке - от 10 до 40 долларов США. ${ }^{8}$ Будущее развитие Арктики как место на котором проводится освоение энергетических ресурсов зависит от продолжения роста спроса и цен, а так же от технологических прорывов и развития политической ситуации в странах Арктики, особенно в Российской федерации.

7 Byers, Who Owns the Arctic?, 10.

8 Kristine Offerdal, "High North Energy: Myths and Realities," in Security Prospects in the High North, 169. 


\section{Российская стратегия в отношении Арктики}

Дальний Север всегда занимал особое место в принятии стратегических решений российским политическим и военным истеблишментом. После распада Советского Союза и последовавшего периода жесткой экономии бюджетных средств, российская Арктика (и в частности Северный флот) стала объектом особого внимания со стороны правящей элиты Москвы. Идея Арктики как стратегический бастион впервые была выдвинута русским адмиралом Горшковым. В советской эпохе, основой военной доктрины была опора на межконтинентальные баллистические ракеты (МБР) наземного базирования. Сейчас, однако, Москва ставит ударение на «силы ответного удара» подводного базирования. Даже в тяжелые времена 1990-х, российский Северный флот всегда получал достаточно денег, чтобы поддерживать свои ядерные подводные лодки и инфраструктуру в оперативной готовности. Ядерное сдерживание является ключевым элементом политики безопасности России и символом статуса России мировой сверхсилы. Наиболее важные ядерные морские силы базируются на Кольском полуострове, находящегося за Полярным кругом.

В настоящее время основные силы Северного флота России включают одиннадцать стратегических подводных лодок, три атомные подводные лодки с крылатыми ракетами, более семидесяти судов различных рангов, одну бригаду морской пехоты, и более восьмидесяти самолетов. Все базы Северного флота находятся в Арктике, в основном в Мурманской области. Важно также отметить, что Россия обладает огромным флотом из семи атомных ледоколов, флот, который Россия надеется расширить до четырнадцати к 2020 году. ${ }^{9}$

В 2007 году президент Путин отдал приказ о возобновлении регулярного патрулирования в воздухе над Северным Ледовитым океаном. Воздушное патрулирование начали проводить стратегические бомбардировщики (Ту-95, Ту-160) и дальние противолодочные патрульные самолеты (Ту-142). В 2007 году русские бомбардировщики проникали в контролируемое Командованием воздушно-космической обороны Северной Америки (NORAD) воздушном пространстве восемнадцать раз. В феврале 2009 года два Ту-95 вошли в воздушное пространство Канады, буквально за день до официального визита президента США Барака Обамы. ${ }^{10}$ В августе 2009 года две русские подводные лодки проекта 971, класса Щука-Б были отправлены на патрулирование в непосредственной близости от Канадской границы. Генерал Шаманов, который отвечал за военную подготовку в русском Генеральном штабе, заявил: «После реакции на территориальные претензии России в Арктике, в моей дивизии сразу же начали планирование подготовки формирований, которые могли бы оказаться востребованы в боевых миссиях в Арктике». ${ }^{11}$

9 Blank, Russia in the Arctic, 80.

10 Byers, Who Owns the Arctic?, 11.

11 Blank, Russia in the Arctic, 44. 
Кроме того, в 2007 году, русская мини подводная лодка погрузилась на глубину 4000 метров в Северном ледовитом океане и оставила русский флаг на морском дне. «Крайний Север является русским. Мы не отдадим его никому!», заявил Артур Чилингаров, известный полярный исследователь и член правящей партии «Единая Россия». В сентябре 2008 года Совет Безопасности России принял документ под названием «Основы русской государственной политики в Арктике до 2020 года и на последующий период». Этот документ устанавливает намерения государства по укреплению позиций России в регионе путем развертывания вооруженных сил и пограничных войск, чтобы гарантировать безопасность арктической территории России. Стратегия национальной безопасности, которая была принята в 2009 году и подписана тогдашним президентом Медведевым, определяет Арктику как стратегический для безопасности России регион. Этот документ обозначил необходимость создания специальных воинских частей в целях защиты Крайнего Севера. Список других приоритетов включает в себя эксплуатацию природных ресурсов региона, обеспечение национальных интересов России на континентальном шельфе, а также создание инфраструктуры и развитие судоходства по Северному морскому пути. Россия настаивает на свои законные права на морское дно, которое является продолжением ее континентального шельфа. Комиссия ООН по границам континентального шельфа попросила Россию предоставить более конкретные геологические и геофизические доказательства того, что хребты Ломоносова и Менделеева являются продолжением континентального шельфа России. Следующий срок в 2013 году. Если заявление будет одобрено, Россия будет находиться в полном владении Северного морского пути, а также значительной части Северного Ледовитого океана и огромных запасов нефти и природного газа. ${ }^{12}$

Ощущение того, что США и НАТО являются основными угрозами национальной безопасности России, глубоко проникает в психологию русского политического и военного истеблишмента. Руководство России подозревает, что западные страны имеют тайные планы, и что они хотят бросить вызов или даже вытеснить Россию как основного игрока в Арктике. Ренационализация Россией своего энергетического сектора от иностранной собственности является одним из шагов, которые Москва предприняла с целью свести к минимуму свою зависимость от Запада. Но Россия по-прежнему остро нуждается в прямых иностранных инвестициях (ПИИ) в экономику, особенно в области технологий и модернизации нефтяной и газовой промышленности. До сих пор русские военные амбиции в регионе были больше риторикой, чем действительностью. Большинство националистического пыла было предназначено для внутреннего потребления, чтобы показать, что «тандем» Путин-Медведев являются единственными истинными патриотами. Во время президентства Медведева, основные проблемы были глобальный экономический кризис, «перезагрузка» отношений с Соединенными Штатами, и мирная передача власти обратно Путину. Арктика не была в верхней части этого списка.

\footnotetext{
12 Там же, 49.
} 
Для регулирования развития и юрисдикции в Арктике, важно понимать, что только путем сотрудничества арктические страны могут преодолеть разногласия между собой и проблемы, которые породит изменение климата в регионе. Арктический совет является идеальным форумом для нахождения общего языка. Он дает арктическим странам возможность решить целый ряд проблем, от загрязнения и охраны окружающей среды, до прав на судоходство и суверенитет над континентальным шельфом. Сотрудничество в Арктике может стать хорошей платформой для взаимопонимания и в других частях мира. Даже с новым крупным игроком - более уверенной и напористой Россией - проблемы, связанные с территориальными спорами и новыми транспортными маршрутами, имеют только один путь разрешения, путь переговоров и дипломатии. 
ЛЕTо 2012

\section{Литература}

Byers, Michael. Who Owns the Arctic? Understanding Sovereignty Disputes in the North . Vancouver, BC: Douglas \& McIntyre, 2010.

Hoel, Alf Håkon. "The High North Legal-Political Regime." In Security Prospects in the High North: Geostrategic Thaw or Freeze?. Rome: NATO Defense College, 2009.

Stephen, Blank. Russia in the Arctic . Carlisle, PA: Strategic Studies Institute Papers, U.S. Army War College, 2011. 